\title{
EC 103 e a Violação de uma Conquista Social: a Inconstitucionalidade do Restabelecimento da Idade Mínima para Aposentadoria Especial
}

\section{EC 103 and the Violation of a Social Achievement: the Unconstitutionality of the Minimum Age Restoration for Special Retirement}

\author{
Marcelo Gonçalves da Silva
}

Gazda \& Siqueira Advogados. PR, Brasil.

E-mail: marcelogoncalvesadv@hotmail.com

\begin{abstract}
Resumo
A Declaração Universal dos Direitos do Homem fundou as bases dos princípios de proteção à dignidade da pessoa humana. Dentre esses princípios gerais, está a ideia de proibição de instituição de normas ou políticas públicas que impliquem em retrocesso nas garantias fundamentais. A partir da premissa de que o Brasil é signatário da DUDH, o presente trabalho tenta responder ao seguinte questionamento: A Emenda Constitucional $n^{\circ} 103$ ao modificar e reintroduzir no ordenamento jurídico a idade mínima como requisito de admissibilidade para a concessão de aposentadoria especial, implicou em retrocesso social no âmbito do direito previdenciário? Seria a Emenda inconstitucional?

Palavras-chave: Aposentadoria Especial. Reforma da Previdência. Proibição do Retrocesso Social.
\end{abstract}

\begin{abstract}
The Universal Declaration of Human Rights laid the foundations for the principles of protection of the dignity of the human person. Among these general principles, there is the idea of prohibiting the establishment of rules or public policies that imply a setback in fundamental guarantees. Based on the premise that Brazil is a signatory to UDHR, the present work tries to answer the following question: Constitutional Amendment 103, by modifying and reintroducing the minimum age as an admissibility requirement for the granting of special retirement, implied in social setback within the scope of social security law? Was the Amendment unconstitutional?
\end{abstract}

Keywords: Special Retirement. Pension Reform. Prohibition of Social Setback.

\section{Introdução}

A Emenda Constitucional 103 reformulou as regras de acesso à aposentadoria especial, criando uma regra de transição por pontos e uma regra permanente que reintroduziu a idade mínima de 60 anos como requisito de elegibilidade, além dos 25 anos de exercício na atividade considerada especial.

Um problema jurídico de difícil compreensão por parte da população e de parte da comunidade jurídica é a necessidade de aposentadoria precoce dos profissionais que, em razão da natureza de suas atividades, estão expostos ao risco à sua integridade física, ao risco químico, biológico ou físico, como forma de efetivar a proteção ao individuo e à sua capacidade de trabalho.

Essas peculiaridades da exposição ao risco laboral justificam a retirada precoce da atividade a que se sujeitam os profissionais que se habilitam à aposentadoria especial.

Para analisar esse ponto específico da EC 103 (a reinserção da idade mínima no ordenamento jurídico) partese do pressuposto de que existência do Estado se justifica essencialmente na efetivação da proteção ao indivíduo, e ainda, que o espírito norteador da previdência social é a necessidade de proteção à perda da capacidade para o trabalho.

A retirada precoce do ambiente laboral fez parte de um processo de evolução do sistema previdenciário brasileiro, e foi integrado ao nosso ordenamento desde 1960, e sem a exigência de idade mínima, desde 1968, adquirindo deste modo o status de uma garantia fundamental, um direito social adquirido que não pode ser suprimido, sob pena de se infringir a Declaração Universal dos Direitos Humanos e todos os pactos a ela correlatos dos quais o Brasil é signatário, além da evidente contradição ao texto constitucional.

A pergunta a ser respondida, portanto, é se a EC 103 ao modificar os critérios de concessão do benefício de aposentadoria especial, reintroduzindo um critério já há tempos excluído do ordenamento jurídico, positivou uma violação a um direito social adquirido em contrariedade ao princípio geral da Declaração Universal dos Direitos Humanos de proibição do retrocesso social?

\section{Desenvolvimento}

\subsection{Qual a finalidade do Estado?}

A simplicidade do questionamento pode levar à tentadora impressão de que a resposta é igualmente simples, nada mais distante da verdade, pois há tempos a indagação desafia respostas das mais diversas.

A pergunta é recorrente no estudo do Direito, da Filosofia e da Sociologia (e de toda ciência que se dedica de algum modo ao estudo da organização social humana), e atrai respostas 
diversas tanto em conteúdo quanto em complexidade. É fato que enquanto persistir a necessidade humana da tutela do Estado a questão será sempre atual. De todo modo, o entendimento jurídico (que nos interessa no momento) sobre o que é o Estado e quais suas funções vem evoluindo ao longo do tempo.

Pode-se dizer de forma simples, com o risco de incorreção conceitual inerente às reduções simplistas, que o Estado tem como objetivo geral a proteção dos indivíduos que o compõe.

A ideia de que a finalidade primária do Estado é a proteção integral do indivíduo encontra respaldo nos mais diversos textos constitucionais mundo afora, contudo, é na Declaração Universal dos Direitos do Homem que ela encontra sua expressão definitiva.

Nas palavras de BOBBIO (2004) a Declaração Universal dos Direitos do Homem congrega a proteção a direitos naturais históricos, que nascem no início da era moderna, juntamente com a concepção individualista da sociedade, e tornam-se um dos principais indicadores do progresso histórico.

A DUDH de 1948 foi um divisor de águas na evolução do pensamento jurídico, ao congregar o discurso liberal e social de cidadania e reforçar a ideia de que a proteção do indivíduo se faz por meio da proteção aos direitos individuais (civis e políticos), os quais por sua vez são condição de realização dos direitos econômicos, sociais e culturais.

Deste modo, a DUDH estabeleceu a premissa da indivisibilidade dos direitos humanos, de maneira que proteção do indivíduo pelo Estado exige a proteção aos direitos individuais tomados em sua completude, de forma que se algum deles for violado, todos os demais também o serão.

A finalidade do Estado foi positivada no texto do artigo 25 da DUDH, que estabeleceu a garantia de que

todo homem tem direito a um padrão de vida capaz de assegura a si e a sua família saúde e bem estar, inclusive alimentação, vestuário, habitação, cuidados médicos e os serviços sociais indispensáveis, e direito à segurança em caso de desemprego, doença, invalidez, viuvez, velhice ou outros casos de perda de meios de subsistência em circunstâncias fora de seu controle.

A partir da premissa de que a proteção do indivíduo é a função do Estado, o reconhecimento e compromisso global de proteção aos direitos do homem estabelecido com a DUDH se tornam um passo natural e previsível na evolução da proteção jurídica do indivíduo.

O pós-guerra consolidou o Estado Democrático de Direito como paradigma da proteção e realização dos direitos do homem, e o necessário estabelecimento dos princípios básicos de existência digna da vida humana.

Assim, o reconhecimento dos direitos do homem pelos signatários da DUDH concretizou a ideia de que a democracia e a defesa dos direitos humanos são pilares que se correlacionam para a manutenção da paz, como lecionou Bobbio (2004), para quem os Direitos do homem, democracia e paz são três momentos necessários do mesmo movimento histórico, pois sem direitos do homem reconhecidos e protegidos não há democracia e sem democracia não existem condições mínimas para a solução pacífica dos conflitos.

Portanto, de modo reducionista não é errado dizer que a função primária do Estado é a proteção do indivíduo, e essa deve ocorrer em diversos estágios diferentes da vida.

Nesse contexto, a necessidade protetiva coberta pelo sistema previdenciário é justamente a impossibilidade individual de produzir sua própria subsistência, seja pela incapacidade laboral decorrente de acidente ou doença, seja essa incapacidade decorrente do processo de envelhecimento.

\subsection{A Proibição ao Retrocesso Social}

A Declaração Universal dos Direitos do Homem de 1948 tem como objetivo principal nortear o desenvolvimento de uma ordem pública mundial alicerçada no respeito à dignidade da pessoa humana, e o fez a partir da consagração de diversos valores básicos universais, intrínsecos a toda pessoa humana, declarando-a titular de direitos iguais e inalienáveis.

Já em seu art. $1^{\circ}$ a DUDH destaca os dois pilares que conceituam a dignidade humana: "Todas as pessoas nascem livres e iguais em dignidade e direitos. São dotadas de razão e consciência e devem agir em relação umas às outras com espírito de fraternidade".

$\mathrm{O}$ desenvolvimento de uma sociedade que consagre a proteção aos direitos humanos individuais e universais é um objetivo a ser perseguido e protegido, pois, nos lugares onde o direito é impotente, a sociedade corre o risco de precipitar-se na anarquia; onde o poder não é controlado, corre o risco do despotismo (BOBBIO, 1997).

A proteção aos direitos humanos universais, tomados genericamente como proteção à dignidade humana, pode ser vista como a materialização jurídica do conhecido pensamento de Kant (2002), para quem o homem e, de maneira geral, todo o ser racional, existe como fim em si mesmo, e não apenas como meio para o uso arbitrário desta ou daquela vontade.

Imbuídas desse espírito humanista garantidor de direitos universais e intrínsecos à vida humana, lastreados na ideia de que o homem é um fim em si, diversos Estados passaram a inserir em seu sistema jurídico a proteção aos direitos sociais, por vezes elevando-os ao status de direito fundamental.

Os direitos sociais envolvem uma ampla gama de direitos, dentre os quais podemos citar exemplificativamente a proteção do trabalho, o direito à saúde e o direito à educação. A efetiva proteção a esses direitos ocorrem na limitação da jornada de trabalho, na imposição de pisos salariais e na participação nos lucros da empresa, bem como na proteção ao direito de greve e de sindicalização, além de outros.

Deste modo, a elevação dos direitos sociais ao status de proteção constitucional tem como claro objetivo a preservação do ser humano e, por isso, pode-se dizer que integram os direitos fundamentais, principalmente porque não se pode pensar em exercício de liberdades, de preservação do princípio 
da dignidade humana, sem que o denominado mínimo vital seja observado (NUNES JÚNIOR, 2009).

Os direitos sociais são considerados fundamentais porque sem eles a pessoa humana não consegue existir ou não é capaz de se desenvolver e de participar plenamente da vida (DALLARI, 1988).

Por sua vez, Alexandre de Moraes (2006, p. 177) afirma que os

Direitos sociais são direitos fundamentais do homem, caracterizando-se como verdadeiras liberdades positivas de observância obrigatória em um Estado Social de Direito tendo por finalidade a melhoria de condições de vida aos hipossuficientes, visando à concretização da igualdade social, e são consagrados como fundamentos do Estado democrático, pelo artigo $1^{\circ}$, IV da Constituição Federal.

A preservação material do ser humano realizada por meio da proteção aos direitos sociais fundamentais, tomados como efetivação da proteção à dignidade humana universal e indivisível, é a face mais aparente da teoria do mínimo existencial, cuja compreensão se faz necessária ao prévio estudo da proibição do retrocesso social.

A teoria do mínimo existencial é inerente à teoria dos direitos fundamentais humanos universais, por meio dela se realiza o estudo, definição e criação de um referencial teórico a fim de respaldar as lutas contra a exclusão social e a miséria, servindo como um elemento teórico adicional para fundamentação de decisões judiciais nas quais se pretende proteger a dignidade humana.

Em uma redução didática e simplificadora, a teoria do mínimo existencial não pode ser dissociada dos direitos humanos, e possui como meta a reposta ao questionamento: quais os direitos e garantias mínimos a serem protegidos para efetivação dos direitos humanos?

É nesse contexto que a DUDH estabelece as premissas de vedação ao retrocesso social, que em sentido amplo funciona como um princípio geral de direito universal, impedindo que determinado Estado retroceda ou exclua um determinado direto fundamental sem que proponha uma contrapartida igual ou superior do ponto de vista social e jurídico.

Portanto, a EC 103 precisa ser analisada em confronto com tratados internacionais dos quais o Brasil e signatário: a Declaração Universal dos Direito do Homem, o Pacto de San Jose da Costa Rica, o Pacto Internacional dos Direitos Civis e Políticos (PIDCP) e o Pacto Internacional dos Direitos Econômicos, Sociais e Culturais (Pidesc) ${ }^{1}$.

É no $\S 1^{\circ}$, artigo $2^{\circ}$ do $\operatorname{Pidesc}^{2}$ que encontramos a determinação explícita para os signatários da observação de dois princípios: a da implementação progressiva e o da proibição do retrocesso.

O princípio da proibição do retrocesso social apresenta dois sentidos: um positivo representado pela ideia de progressão constante no nível de efetivação dos direitos sociais, e um negativo, que consiste no zelo por uma produção legislativa que não suprima ou reduza o nível de efetivação ou consistência normativa já alcançado.

Assim, a observação do princípio universal da proibição do retrocesso social protege o titular do direito a uma eventual eliminação de uma conquista jurídico social já inserida no ordenamento jurídico, uma espécie de proteção ao "direito social adquirido".

Alexy (2012) melhor exemplifica essa proteção do indivíduo titular do direito social fundamental em face do Estado, o esclarecer que

o terceiro grupo de direitos a ações estatais negativas é constituído pelos direitos a que o Estado não elimine determinadas posições jurídicas do titular do direito. [...] Quando se proíbe a expressão de determinadas opiniões, elimina-se uma posição de a: a permissão de expressar essas opiniões. Uma tal proibição pode ser encarada sob dois aspectos: sob o aspecto do embaraço de uma ação e sob o aspecto da eliminação de uma posição. No caso de ações que não são atos jurídicos, o primeiro aspecto é o decisivo. Mais uma vez é aconselhável reduzir a diversidade a uma forma padrão simples, como a seguinte: a tem, em face do Estado, um direito a que este não elimine a posição jurídica RP de a. A existência de uma posição jurídica significa que uma norma correspondente (individual ou universal) é válida. $\mathrm{O}$ direito do cidadão, contra o Estado, a que este não elimine uma posição jurídica sua é, nesse sentido, um direito a que o Estado não derrogue determinadas normas.

Sobre a proteção constitucional e o princípio do não retrocesso social, Canotilho (2003) pontuou "quer dizerse que os direitos sociais e econômicos (ex.: direito dos trabalhadores, direito à assistência, direito à educação), uma vez obtido um determinado grau de realização, passam a constituir, simultaneamente, uma garantia institucional e um direito subjetivo. A "proibição de retrocesso social" nada pode fazer contra as recessões e crises econômicas (reversibilidade fática), mas o princípio em análise limita a reversibilidade dos direitos adquiridos (ex.: segurança social, subsídio de desemprego, prestações de saúde), em clara violação do princípio da proteção da confiança e da segurança dos cidadãos no âmbito econômico, social e cultural, e do núcleo essencial da existência mínima inerente ao respeito pela dignidade da pessoa humana.

Portanto, além de serem eficazes, os direitos sociais fundamentais estão integralmente sujeitos ao princípio da proibição do retrocesso social, a fim de impedir que o Estado elimine conquistas sociais históricas no âmbito jurídico.

Essa proteção especial se faz necessária, pois a história demonstra que a simples constituição de um Estado Democrático não garante por si um direcionamento em sentido

1 Ratificado no Brasil pelo Decreto n ${ }^{\circ}$ 591, de 6 de julho de 1992

2 Artigo $2^{\circ}$ - 1. Cada Estado Parte do presente Pacto compromete-se a adotar medidas, tanto por esforço próprio como pela assistência e cooperação internacionais, principalmente nos planos econômico e técnico, até o máximo de seus recursos disponíveis, que visem a assegurar, progressivamente, por todos os meios apropriados, o pleno exercício dos direitos reconhecidos no presente Pacto, incluindo, em particular, a adoção de medidas legislativas 
único e ascendente rumo ao progresso jurídico e moral. Como leciona Gomes (2001) a Democracia é um processo, e por isso, tem caráter dinâmico. Está em constante mutação. Pode evoluir, como, também, regredir. É possível realizá-la aumentar sua presença no espaço social, ou, então, sufocá-la.

Em nosso ordenamento, somente uma interpretação sistêmica do texto constitucional permite inferir que o princípio da proibição ao retrocesso social foi adotado de modo implícito, cujos indícios mais evidentes são adoção da ideia de Estado Democrático de Direito e da adoção da dignidade da pessoa humana como princípio fundamental.

\subsection{Evolução Histórica da Aposentadoria Especial no Brasil}

A aposentadoria especial foi introduzida na proteção previdenciária nacional por meio da Lei 3.807 de 26 de agosto de 1960, conhecida como LOPS - Lei Orgânica da Previdência Social, e que foi inicialmente regulamentada pelo Decreto 53.831 de 25 de março de 1964.

A lei trazia a previsão de obtenção de aposentadoria especial ao segurado que contasse cumulativamente com cinquenta anos de idade, quinze anos de contribuição e comprovasse o exercício de atividade profissional insalubre, penosa ou considerada perigosa, pelo período de 15, 20 ou 25 anos a depender da atividade e do risco desenvolvido.

O regulamentador Decreto 53.831, 25 de março de 1964 apresentou apenas um rol exemplificativo de agentes de risco e ocupações, com os correspondentes prazos de 15, 20 ou 25 anos. A aposentadoria especial, portanto, foi introduzida no sistema previdenciário brasileiro sem que houvesse uma definição taxativa de quais seriam as atividades insalubres, penosas ou perigosas.

Com a edição da Lei no 5.440-A, de 23 de maio de 1968 que alterou o art. 31 da Lei no 3.807, de 1960, que houve a supressão da exigência da idade de cinquenta anos para a concessão de aposentadoria especial, em relação aos serviços e atividades profissionais constantes do Quadro Anexo ao Decreto no 53.831, de 1964.

Em 1979, o Decreto 83.080 alterou o Decreto 53.831, e apresentou 2 quadros diferentes no qual classificou as atividades profissionais de acordo com os agentes nocivos - código 1.0.0 e as atividades profissionais, segundo os grupos de profissionais - código 2.0.0.

Tais alterações permaneceram em vigência meso após a promulgação da Constituição em 1988, e da edição das Leis 8.212 e 8.213 em 24 de julho de 1991.

Somente em 1995 com a edição de Lei 9.032 é que foi extinta a concessão de aposentadoria especial por atividade profissional, determinando a necessidade de comprovação de exercício de atividade com exposição aos agentes químicos, físicos, biológicos ou associação de agentes prejudiciais à saúde ou à integridade física, pelo período equivalente ao exigido para a concessão do referido benefício, assim como, comprovação pelo segurado do tempo de trabalho permanente, não ocasional nem intermitente, nas condições que prejudicassem a saúde ou integridade física durante o período mínimo fixado em lei, que permaneceu 15, 20 ou 25 anos.

Posteriormente, houveram diversas modificações pontuais trazidas introduzidas pela MP 1.523 , de 11 de outubro de 1996, pelo Decreto 2.172, de 1997, pela medida provisória - MP 1.729, de 2 de dezembro de 1998, convertida na lei 9.732, de 11 de dezembro de 1998, pelo Decreto 3.048, de 6 de maio de 1999, pelo Decreto 4.032, de 26 de novembro de 2001, pela MP 83, de 12 de dezembro de 2002, pelo Decreto 4.882, de 18 de novembro de 2003, e pelo Decreto 8.123, de 2013, antes da significativa alteração promovida pela EC 103.

No entanto, essas diversas modificações ao longo dos anos, em geral trataram de estabelecer e padronizar os procedimentos administrativos de análise e concessão do benefício, e em alguns casos promovendo a ampliação dos agentes nocivos e dos casos nos quais a exposição ao agente de risco e sua nocividade é presumida.

O ponto que de grande relevância para este estudo em particular, diz respeito ao fato de que, desde o momento em que foi introduzida no ordenamento jurídico previdenciário brasileiro, a aposentadoria especial está umbilicalmente atrelada à ideia de prevenção.

\subsection{A aposentadoria especial e a proteção do indivíduo}

A proteção previdenciária ao segurado está ligada de um modo geral, à ocorrência de evento futuro que pode ser certo ou incerto, e nesse universo estão incluídos os benefícios programados, para os quais se estabelece requisitos de tempo de contribuição específicos para a concessão de um determinado benefício, e também os benefícios por incapacidade, os quais estão vinculados à ocorrência de um quadro incapacitante motivado por doença ou ocorrência de sinistro.

Contudo, os benefícios previdenciários possuem como ponto convergente a ideia de proteção do segurado à perda da capacidade para o trabalho, seja em razão de sinistros e moléstias, seja em razão das limitações de trabalho naturalmente impostas pelo processo de envelhecimento.

A aposentadoria especial pode em uma observação superficial destoar desse contexto, no entanto, sua razão de existir é a mesma que os demais benefícios, e de modo bastante singular também protege a perda da capacidade laboral.

Essa proteção ocorre de modo diferenciado na aposentadoria especial, a aposentadoria especial se trata de um benefício ao segurado que tiver trabalhado sujeito a condições de trabalho que prejudiquem a saúde ou a integridade física, durante 15 (quinze), 20 (vinte) ou 25 (vinte e cinco) anos, conforme dispuser a lei.

A especialidade que dá nome ao benefício advém de sua característica particular de que, nessa modalidade de benefício, a proteção à capacidade produtiva/de trabalho do segurado ocorre de modo preventivo, ou seja, o trabalhador 
é retirado do meio laboral nocivo (insalubre/perigoso) a fim de que seja evitado um evento futuro incerto, porém, de alta previsibilidade, ou de certeza relativa.

Segundo Horvath Júnior (2014), esta modalidade de aposentadoria é direito subjetivo excepcional de quem preenche aspecto especial porque requer, além do tempo de serviço, a exposição ao risco.

Ampliando o conceito, Martins (2008, p. 57) esclarece que

trata-se de um benefício de natureza extraordinária, tendo por objetivo compensar o trabalho do segurado que presta serviços em condições adversas à sua saúde ou que desempenha atividade com riscos superiores aos normais.

Sua inclusão na redação original dos arts. $40, \S 4^{\circ}$ e $201, \S$ $1^{\circ}$ da Constituição Federal de 1988, configurou um importante avanço social no direito fundamental à previdência social e à proteção à dignidade humana.

Isto porque, os trabalhadores que exercem atividades de risco e aqueles cujas atividades são exercidas sob condições especiais que prejudiquem sua saúde ou integridade física, são, sob a ótica da infortunística, imediatamente retirados do grupo geral de trabalhadores e inseridos em um grupo de risco acentuado e por vezes de iminência, no qual a perda da capacidade de trabalho de forma antecipada, em comparação ao grupo geral de trabalhadores, é muitas vezes maior e de certa forma previsível.

Por risco, devemos entender a probabilidade de ocorrência de um dano futuro e incerto, e por iminência de dano a relativa certeza de sua ocorrência, nos dois casos, balizados por critérios científicos fornecidos medicina do trabalho.

Deste modo, o caráter preventivo da aposentadoria especial se evidencia pelo afastamento prematuro do trabalhador de atividades laborais que, em razão de exposição a agentes de risco, apresentam uma certeza reativa de consolidação de danos à saúde decorrentes da exposição em longo prazo.

Como explicou Ribeiro (2009), a aposentadoria especial é um benefício que visa garantir ao segurado do Regime Geral da Previdência Social uma compensação pelo desgaste resultante do tempo de serviço prestado em condições prejudiciais.

Uma vez que os trabalhadores em atividades consideradas especiais compõem um grupo de risco acentuado e por vezes de iminência, no qual, em comparação ao grupo geral de trabalhadores, a perda da capacidade de trabalho de forma antecipada é muitas vezes maior, e de certa forma previsível, se fez necessária a previsão de que esse grupo se retirasse mais cedo das atividades de risco, de forma a evitar a previsível ocorrência de um infortúnio previsível (doença ou acidente) e diminuir o custo social decorrente de uma incapacidade temporária ou permanente, ou até mesmo do evento morte.

Essas peculiaridades caracterizam a aposentadoria especial como um benefício previdenciário programado extraordinário, cuja prestação assume caráter preventivo, protetivo e indenizatório.

\subsection{A inconstitucionalidade do restabelecimento da idade mínima para aposentadoria especial}

A idade mínima como um dos requisitos de elegibilidade para a concessão de aposentadoria especial vigorou no Brasil entre agosto de 1960 e maio de 1968. Após esse período, inúmeras alterações normativas a nível legislativo e regulamentar, alteraram os requisitos e a forma de concessão da aposentadoria especial, entretanto, a idade mínima não foi objeto e tampouco foi reintroduzida por nenhuma das modificações normativas ocorridas após 1968.

Contudo, a Emenda Constitucional 103 apresentou uma regra de transição "até que lei complementar disponha sobre”, que meio século depois (51 anos mais precisamente) reintroduziu no ordenamento jurídico a idade mínima como um dos requisitos de elegibilidade à aposentadoria especial.

A nova "regra transitória", com ares de permanente, estabeleceu as idades mínimas de 55, 58 e 60 anos de idade para os trabalhadores em atividades especiais de 15,20 e 25 anos de contribuição respectivamente, o que representa na prática, a supressão da aposentadoria especial.

A conclusão não é exagerada se considerado o objetivo existencial da aposentadoria especial, o que permite o legítimo questionamento: se a aposentadoria especial surgiu como meio de proteger a capacidade produtiva do segurado, retirando-o antecipada e preventivamente do meio nocivo (insalubre/ perigoso) a fim de que seja evitado um evento futuro incerto, porém, de alta previsibilidade, ou de certeza relativa, qual a utilidade (do ponto de vista da infortunística) de se manter o segurado exposto ao risco até os 60 anos?

Em uma suposição hipotética, mas sabidamente comum na realidade laboral, um segurado que inicie seu trabalho aos 20 anos de idade em atividades especiais de 25 anos (aqui tomada por ser a mais comum), teria até novembro de $2019 \mathrm{o}$ direito de se aposentar aos 45 anos de idade. Pela nova regra permanente esse mesmo trabalhador somente se aposentará aos 60 anos de idade.

Com isso, haverá a manutenção da exposição ao ambiente de risco insalubre ou perigoso por um período adicional de 15 anos, aumentando de forma significativa o risco da ocorrência de um evento futuro de certeza relativa, ou, dito de outro modo, aumentam as chances de ocorrência de doenças ou de ofensas à integridade física do trabalhador, quase transformando a certeza relativa em absoluta.

A gravidade desta opção legislativa pode ser observada pela análise da recente decisão proferida pelo STF no Tema de repercussão geral 709 , em que se analisou a constitucionalidade do $\S 8^{\circ}$ do art. 57 da Lei 8.213/91, sendo definida a tese de que "É constitucional a vedação de continuidade da percepção de aposentadoria especial se o beneficiário permanece laborando em atividade especial ou a ela retorna, seja essa atividade especial aquela que ensejou a aposentação precoce ou não". 
A decisão do STF se deu justamente em razão do risco de ocorrência de evento futuro (sinistro ou doença), inerente à atividade desenvolvida, o que torna efetiva a necessidade de afastamento da atividade especial do segurado que se aposentou justamente para que se elimine esse risco futuro, pois do contrário não haveria razão para a existência da aposentadoria especial.

Portanto, não há cálculo atuarial que justifique o risco de se reinserir no ordenamento a exigência de idade mínima para a aposentadoria especial, principalmente quando essa idade mínima é apenas 5 anos mais baixa do que a idade para a aposentadoria programada (antiga aposentadoria por idade) que se atinge aos 65 anos.

Como já dito, a proibição ao retrocesso social se constitui em uma espécie de "direito social adquirido", o que proíbe o legislador infraconstitucional (e em última análise o Estado) a estabelecer normas ou políticas públicas regressiva.

A EC 103 precisa ser analisada em confronto com tratados internacionais dos quais o Brasil e signatário: a Declaração Universal dos Direito do Homem, o Pacto de San Jose da Costa Rica, o Pacto Internacional dos Direitos Civis e Políticos (PIDCP) e o Pacto Internacional dos Direitos Econômicos, Sociais e Culturais (Pidesc).

É somente a partir da análise conjunta da Constituição, da EC 103, e dos pactos acima nominados que se pode constatar o retrocesso social decorrente por conta do restabelecimento da idade mínima dentre os requisitos de concessão da aposentadoria especial.

Justamente dessa análise conjunta que se estabelece o vínculo e entre o dever estatal de proteção ao indivíduo e a evolução do direito previdenciário para, atendendo à necessidade de proteção do indivíduo, retirar do ordenamento jurídico a idade mínima dos requisitos de acesso à aposentadoria especial, com o fito de remover o trabalhador de forma preventiva e antecipada de situação de risco.

Trata-se de uma conquista social histórica, um direito social adquirido: a proteção do segurado à perda da capacidade para o trabalho individual (manutenção da própria subsistência) com a sua retirada preventiva do trabalho insalubre por meio da concessão de um benefício previdenciário.

A reinserção da idade mínima dentre os requisitos de admissibilidade à percepção da aposentadoria especial, na forma em que promovida pela EC 103, mais de meio século depois de sua retirada do ordenamento jurídico, a caracteriza como uma norma regressiva, e, portanto, inconstitucional.

Com efeito, a constatação de que uma norma ou uma política pública é regressiva acarreta a presunção de sua inconstitucionalidade e a inversão do ônus da prova de sua razoabilidade e proporcionalidade (ABRAMOVICH; COURTIS, 2002, em tradução livre).

A inversão do ônus da prova quanto à razoabilidade e proporcionalidade da norma é necessária à concretização do acesso à justiça nas arguições de inconstitucionalidade.

Foi como decidiu o ministro Ricardo Lewandowski do
STF, que em liminar concedida no dia 31 de agosto de 2017, na Ação Direta de Inconstitucionalidade (ADI) $n^{\circ}$ 5.595, para suspender a eficácia dos artigos $2^{\circ}$ e $3^{\circ}$ da Emenda Constitucional $n^{\circ} 86 / 105$, confirmou que o retrocesso social "acarreta a presunção de invalidez ou inconstitucionalidade da medida adotada, bem como, transfere ao Estado o ônus da prova quanto à sua razoabilidade."

Nessa situação, o Estado ainda pode justificar a medida adotada, contudo, precisará demonstrar que "examinou todas as alternativas existentes e justificá-las em relação à totalidade dos direitos previstos no Pacto e no contexto de utilização do máximo dos recursos disponíveis, consagrando assim a inversão do ônus da prova" (GOTTI, 2012).

De modo que nos parece clara a regressividade contida na EC 103 ao reintroduzir a idade mínima como requisito de elegibilidade à aposentadoria especial, o que faz presumir sua inconstitucionalidade que necessariamente precisará ser enfrentada em um breve futuro, como parte da pavimentação do caminho da efetivação da proibição do retrocesso social.

\section{Conclusão}

Nenhuma norma jurídica é uma ilha isolada do continente, é antes parte integrante de vasto complexo normativo alicerçado em princípios gerais de direito, cuja observação e efetivação guardam uma relação direta com a consolidação do com o Estado Democrático de Direito.

Essa correlação atrai os países signatários da DUDH e de todos os pactos a ela correlatos à observação das normas de "direitos humanos", como forma de pavimentar a construção e efetivação do Estado Democrático de Direito, e proporcionar a efetivação da finalidade do Estado, que é proteção do indivíduo.

Dentre as normas de direitos inerentes à condição humana está o da proibição do retrocesso social, por meio do qual se próbe a retirada de direitos fundamentais do homem que tenham sido introduzidos no ordenamento.

Nesse contexto específico de proibição ao retrocesso social, a EC 103 reintroduziu no ordenamento jurídico, após 51 anos de exclusão, a idade mínima como requisito de elegibilidade para o acesso à aposentadoria especial.

Este fato configurou um retrocesso social, na medida em que o requisito idade mínima foi suprimido da regra geral previdenciária justamente em razão do fundamento maior de existência da Previdência Social, que é a proteção do indivíduo.

$\mathrm{Na}$ aposentadoria especial ocorre a retirada antecipada de um ambiente que é fonte de risco ocupacional, como forma de proteção de um risco futuro de certeza relativa, pois alguns trabalhos contêm em si o risco de doenças ou à integridade física do segurado, de modo a proteger sua capacidade laboral e manter sua utilidade social.

Essa prevenção ao risco futuro e de certeza relativa, motivou o afastamento da idade mínima por mais de meio século do conjunto de norma previdenciárias, como forma 
de efetivar a garantia de proteção ao indivíduo (finalidade do Estado) por meio da aposentadoria precoce.

Sua reinserção por meio da EC 103 acaba por tornar inútil a existência do conceito de aposentadoria especial, vez que a obrigatoriedade de se atingir os 60 anos de idade em atividades de risco presumido, acaba por tornar a certeza relativa de ocorrência de sinistro (doença ou acidente) em certeza absoluta.

Dito de outro modo, a EC 103 fará com que o segurado permaneça por mais de uma década a mais exposto ao risco químico, físico ou biológico, aumentando o risco social de incapacidade decorrente de sinistros laborais, e retirando de modo implícito a garantia social de proteção ao trabalho, ao meio ambiente do trabalho sadio, e à eficiente proteção previdenciária.

Portanto, por meio da análise conjunta da Constituição e dos pactos internacionais vinculados à DUDH, dos quais o Brasil é signatário, podemos concluir pela inconstitucionalidade presumida da EC 103 em razão de sua expressa regressividade na garantia fundamental de proteção ao trabalho e ao indivíduo.

A inconstitucionalidade da EC 103 precisará ser enfrentada em um breve futuro, a fim de pavimentar nosso complexo e sinuoso caminho de efetivação dos princípios de Direitos Humanos, em especial, o negligenciado princípio da proibição ao retrocesso social.

\section{Referências}

ABRAMOVIC, V.; COURTIS, C. Los derechos sociales como derechos exigibles. Madrid: Editorial Trotta, 2002.

ALEXY, R. Teoria dos direitos fundamentais. São Paulo: Malheiros, 2012;

BOBBIO, N. O tempo da memória - de Senectute e outros escritos autobiográficos. Rio de Janeiro: Campus, 1997.

BRASIL. Supremo Tribunal Federal. Ação Direta de Inconstitucionalidade $\mathrm{n}^{\circ}$ 5.595, Decisão na Medida Cautelar, Distrito Federal. Relator Min. Ricardo Lewandowski, 31 ago. 2017.

CANOTILHO, J.J.G. Direito constitucional e teoria da constituição. São Paulo: Saraiva, 2003.

CASTRO, C.A.P.; LAZZARI, J.B. Manual de Direito Previdenciário. São José: Conceito Editoria, 2010.

DALLARI, D.A. Direitos humanos e cidadania. São Paulo: Moderna, 1988;

GOMES, S.A. Hermenêutica Jurídica e Constituição no Estado de Direito Democrático. Rio de Janeiro: Forense, 2001.

GOTTI, A. Direitos Sociais: fundamentos, regime jurídico, implementação e aferição de resultado. São Paulo: Saraiva, 2012.

HORVATH JÚNIOR. M. Direito Previdenciário. São Paulo: Quartier Latin, 2014.

KANT, I. Fundamentação da metafísica dos costumes. São Paulo: Abril Cultural, 2002.

MARTINS, S.P. Direito da seguridade social. São Paulo: Atlas, 2008

NUNES JÚNIOR, V.S. A cidadania social na Constituição de 1988. São Paulo: Verbatim, 2009;

RIBEIRO, M.H.C.A. Aposentadoria especial: regime geral da previdência social. Curitiba: Juruá, 2009. 